\title{
Genetic analysis of Caveolin-1 and eNOS genes in colorectal cancer
}

\author{
MANUEL CHAVES CONDE ${ }^{1}$, REPOSO RAMIREZ-LORCA ${ }^{2}$, JOSE MIGUEL ESTEBAN LOPEZ-JAMAR ${ }^{3}$, \\ EVA MOLERO ${ }^{2}$, JUAN ANDRES RAMÍREZ-ARMENGOL ${ }^{3}$, JOSE ANDRÉS MORENO NOGUEIRA ${ }^{1}$, \\ MANUEL HIDALGO PASCUAL ${ }^{4}$, AGUSTIN RUIZ ${ }^{2}$, CARLOS GARCÍA MARTÍN-CORDOVA ${ }^{5}$, \\ LUIS MIGUEL REAL ${ }^{2}$ and JOSE LUIS ROYO ${ }^{2}$
}

\author{
${ }^{1}$ Servicio de Oncología Médica, Hospital Universitario Virgen del Rocío, Avda. Manuel Siurot, 41013 Sevilla; \\ ${ }^{2}$ Departamento de Genómica Estructural, Neocodex SL, C/Charles Darwin s/n, Isla de la Cartuja, 41092 Sevilla; \\ ${ }^{3}$ Servicio de Endoscopia, Hospital Clínico San Carlos, C/Dr Martín Lagos, 28040 Madrid; \\ ${ }^{4}$ Servicio de Cirugía General-B, Hospital Universitario 12 de Octubre, C/Cordoba s/n, 28041 Madrid; \\ ${ }^{5}$ Hospital Ramón y Cajal, Ctra Colmenar Viejo Km 9, 28034 Madrid, Spain
}

Received February 22, 2006; Accepted March 25, 2006

\begin{abstract}
Caveolae are involved in physical compartmentalization between different groups of signaling events. Its main component, CAV1, modulates different pathways in cellular physiology. The emerging evidence pointing to the role of CAV1 in cancer led us to study whether different alleles of this gene are associated with colorectal cancer (CRC). Since one of the most characterized enzymes regulated by CAV1 is eNOS, we decided to include both genes in this study. We analyzed five SNPs in 360 unrelated CRC patients and 550 controls from the general population. Two of these SNPs were located within eNOS and three within the CAV1 gene. Although haplotype distribution was not associated with CRC, haplotype TiA (CAV1) was associated with familiar forms of CRC $(p<0.05)$. This was especially evident in CRC antecedents and nuclear forms of CRC. If both CG (eNOS) and TiA (CAV1) haplotypes were taken together, this association increased in significance. Thus, we propose that CAV1, either alone or together with eNOS alleles, might modify CRC heritability.
\end{abstract}

\section{Introduction}

Caveolae are lipid 'rafts' that form detergent-resistant microdomains (50-100 $\mathrm{nm}$ in diameter) in the cellular membrane. These structures are enriched in glycosphingolipids, sphingolipids and cholesterol, together with lipid-modified signaling molecules such as G-proteins, Src-tyrosine kinases and eNOS (1). Caveolae were traditionally associated to different cellular events such as transcytosis and endocytosis,

Correspondence to: Dr Jose Luis Royo, Departamento de Genómica Estructural, Neocodex SL, C/Charles Darwin s/n, Isla de la Cartuja, 41092 Sevilla, Spain

E-mail: jlroyo@neocodex.es

Key words: eNOS, Caveolin-1, colorectal cancer, pyrosequencing, heritability but now their role in signal transduction is not in doubt. These microdomains exert a physical compartmentalization between different groups of signaling events, separating functionally unrelated signaling pathways and, therefore, facilitating cross-talk between related signaling modules (2-4). The proteins responsible for these structures, caveolins-1, -2 and -3 , belong to a family of highly conserved integral membrane proteins. Caveolin-3 has been found only in muscle tissue (5), whilst caveolin-1 and -2 are ubiquitously expressed. Caveolin-1 (CAV1) encodes for a small protein $(22 \mathrm{kDa})$ that constitutes the major component of the caveolae. CAV1 has been found to be necessary and sufficient to form the caveolae both in vitro and in vivo (6). The role of caveolins in different pathologies such as diabetes, muscular dystrophy, Alzheimer and cancer has been widely investigated (7-9).

Some authors have found a differential display of CAV1 in colon cancer cell lines and experimental colon adenocarcinomas when compared to normal tissue $(10,11)$. However, the role of CAV1 in the aberrant cellular physiology is not fully understood. Caveolin-1 gene maps 7q31.1, a frequent unstable region within tumors with a high likelihood of LOH $(12,13)$. There is also evidence that caveolin-1 promoter can be aberrantly methylated in pre-cancerous stages of colorectal cancer, which might be associated with its silencing during tumor development (14). Therefore, caveolin-1 has been proposed to be a tumor suppressor gene (13). However, there is also evidence suggesting a potential role of CAV1 as an oncogene under some circumstances $(11,15,16)$.

One of the enzymes negatively regulated by caveolin-1 is the endothelial nitric-oxide synthase. eNOS is a large (133 kDa) lipid-modified protein found in the caveolae interacting with CAV1 $(17,18)$. As a consequence, the eNOS catalytic activity is inhibited, preventing nitric oxide (NO) production. NO is a pleiotropic regulator, pivotal to multiple biological processes including vasodilation, neurotransmission or immunity. Furthermore, progression of a large majority of human tumors appears to be influenced by NO levels (19). 
Table I. Primers, probes and PCR conditions used for genotyping. ${ }^{a}$

\begin{tabular}{|c|c|c|c|}
\hline Reference & PCR primers $\left(5^{\prime}-3^{\prime}\right)$ & PCR conditions & Pyrosequencing and FRET primers $\left(5^{\prime}-3^{\prime}\right)$ \\
\hline \multicolumn{4}{|l|}{ eNOS } \\
\hline rs1799983 & CACAGCTCTGCATTCAGCAC & $1.5^{\prime}$ at $95^{\circ} \mathrm{C}$, & Су5-CTCTTCCTTCTGCCCCCCGAGCTGGTCC-P \\
\hline (Glu298Asp) & TCCATCCCACCCAGTCAATC & $\begin{array}{l}\text { 2. }\left[30^{\prime \prime}-95^{\circ} \mathrm{C}, 30 "-58^{\circ} \mathrm{C}, 30^{\prime \prime}-72^{\circ} \mathrm{C}\right] \times 50 \\
\text { 3. } 5^{\prime} \text { at } 72^{\circ} \mathrm{C} \text {. }\end{array}$ & CCCCAGATGATCCCCCAGA-FL \\
\hline $\begin{array}{l}\text { rs2070744 } \\
(\mathrm{T} 786 \mathrm{C})\end{array}$ & $\begin{array}{l}\text { TGCCTGGAGAGTGCTGGTGT- } \\
\text { CGATCAGCAGAGAGACTAGG }\end{array}$ & $\begin{array}{l}\text { 1. } 5^{\prime} \text { at } 95^{\circ} \mathrm{C} \text {, } \\
\text { 2. }\left[30^{\prime \prime}-95^{\circ} \mathrm{C}, 20^{\prime \prime}-62^{\circ} \mathrm{C}, 30^{\prime \prime}-72^{\circ} \mathrm{C}\right] \times 50 \\
\text { 3. } 5^{\prime} \text { at } 72^{\circ} \mathrm{C} \text {. }\end{array}$ & GGCTGAGGCAGGGTC \\
\hline \multicolumn{4}{|l|}{ CAV1 } \\
\hline $\begin{array}{l}\text { rs3840634 } \\
\text { (del) }\end{array}$ & $\begin{array}{l}\text { AGACCTGCTTCGGGTCTGCT } \\
\text { Biotin-GGTCATCCATGACTGCCCTG }\end{array}$ & $\begin{array}{l}\text { 1. } 5^{\prime} \text { at } 95^{\circ} \mathrm{C} \text {, } \\
\text { 2. }\left[30^{\prime \prime}-95^{\circ} \mathrm{C}, 30^{\prime \prime}-68^{\circ} \mathrm{C}, 30^{\prime \prime}-72^{\circ} \mathrm{C}\right] \times 50 \\
\text { 3. } 5^{\prime} \text { at } 72^{\circ} \mathrm{C} \text {. }\end{array}$ & $\begin{array}{l}\text { Cy5-AATGTGTGTACCCATTTCAG-P } \\
\text { GGATCATTTCCCATTATACACTCA-FL }\end{array}$ \\
\hline $\begin{array}{l}\text { rs3807990 } \\
(\mathrm{C}>\mathrm{T})\end{array}$ & $\begin{array}{l}\text { AGACCTGCTTCGGGTCTGCT } \\
\text { Biotin-GGTCATCCATGACTGCCCTG }\end{array}$ & $\begin{array}{l}\text { 1. } 5^{\prime} \text { at } 95^{\circ} \mathrm{C} \text {, } \\
\text { 2. }\left[30^{\prime \prime}-95^{\circ} \mathrm{C}, 30^{\prime \prime}-68^{\circ} \mathrm{C}, 30^{\prime \prime}-72^{\circ} \mathrm{C}\right] \times 50 \\
\text { 3. } 5^{\prime} \text { at } 72^{\circ} \mathrm{C} \text {. }\end{array}$ & GTAGGAATCCTCTGCTC \\
\hline $\begin{array}{l}\text { rs6867 } \\
(\mathrm{G}>\mathrm{A})\end{array}$ & $\begin{array}{l}\text { CCATTGTGTGAGCCTATCAG } \\
\text { Biotin-ACGACTCAGGTTTACAGGTG }\end{array}$ & $\begin{array}{l}\text { 1. } 5^{\prime} \text { at } 95^{\circ} \mathrm{C} \text {, } \\
\text { 2. }\left[30^{\prime \prime}-95^{\circ} \mathrm{C}, 30^{\prime \prime}-60^{\circ} \mathrm{C}, 30^{\prime \prime}-72^{\circ} \mathrm{C}\right] \times 50 \\
\text { 3. } 5^{\prime} \text { at } 72^{\circ} \mathrm{C}\end{array}$ & GTAAAGCACTTGCAACC \\
\hline
\end{tabular}

aFRET probes were phosforylated in 3' (P) or labeled with fluorescein (FL).

Recent studies have found that a high expression of eNOS in peritumoral microvessels protects against coloractal tumor metastasis (20). Moreover, evidence can also be found in the literature associating eNOS alleles with different parameters concerning ovarian and vulvar cancers $(21,22)$. In particular, polymorphisms rs2070744 (also known as T786C) and rs1799983 (also named Glu298Asp), have been previously shown to be functional or, at least associated to other pathologies (23-28). Based on these observations, we decided to include both eNOS and CAV1 in the study of our colon adenocarcinoma series. Our aim was to elucidate whether these genes are involved in either the susceptibility or a differential prognosis of the disease.

We studied a total of 910 subjects, consisting of 360 unrelated colorectal cancer (CRC) patients and 550 controls from the general population. We studied whether CAV1 or eNOS is involved in CRC aetiology. Taken into account the studies aforementioned, we selected three single nucleotide polymorphisms (SNPs) within caveolin-1 (rs3807990, rs3840634 and rs6867) as well as two well-characterized SNPs of eNOS (rs2070744 and rs1799983) and compared their distribution between cases and controls.

\section{Materials and methods}

Colorectal cancer cases and controls. A total of 360 cases and 550 controls were included (1:1.5 ratio). All subjects supplied written informed consent, together with a blood sample and a complete questionnaire regarding individual, environmental, familial variables, and pharmacological treatments. Only patients with confirmed histological diagnosis were included in our case series. We considered
CRC-antecedent when at least one first- or second-degree relative also presented CRC. Aggregation indicates at least three independent cases of CRC confirmed among the first- or second-degree relatives. Nuclear cancer was defined when at least one first-degree relative was also diagnosed for CRC.

DNA extraction. We obtained $5 \mathrm{ml}$ of peripheral blood from all patients to isolate germline DNA from leukocytes. DNA extraction was performed automatically according to standard procedures using Magnapure DNA isolation system (Roche, Germany). To perform polymerase chain reactions (PCRs), we prepared aliquots of DNA at a concentration of $5 \mathrm{ng} / \mu 1$. The rest of the stock was cryopreserved at $-20^{\circ} \mathrm{C}$.

Pyrosequencing and FRET assays. Primers and PCR conditions are summarized in Table I. PCR reactions were performed at a final volume of $20 \mu \mathrm{l}$, containing $5 \mathrm{ng}$ of genomic DNA, $1.5 \mathrm{mM} \mathrm{MgCl}, 0.125 \mathrm{mM}$ dNTPs, $2 \mathrm{U}$ of Taq, and $5 \mathrm{pmol}$ of each primer. Amplification cycles were repeated 50x in order to abolish the free biotinylated primers that may interfere with the pyrosequencing reaction. For the SNPs located in CAV1 intron 2, PCR was performed at a final volume of $30 \mu 1$. After amplification, $10 \mu 1$ were separated and rs3840634 (2-bp deletion) was analyzed using Light Cycler technology by means of fluorescence resonance energy transfer (FRET). On the other hand, rs3807990 (C>T) was determined by pyrosequencing using the remaining $20 \mu \mathrm{l}$. As an internal control, $10 \%$ of all DNA samples were independently reextracted from blood and re-typed for each marker. Genotype concordance reached $98 \%$. Unreliable genotypes derived from low-quality DNAs and inconsistent clinical data were discarded from the statistical analysis. 
A)

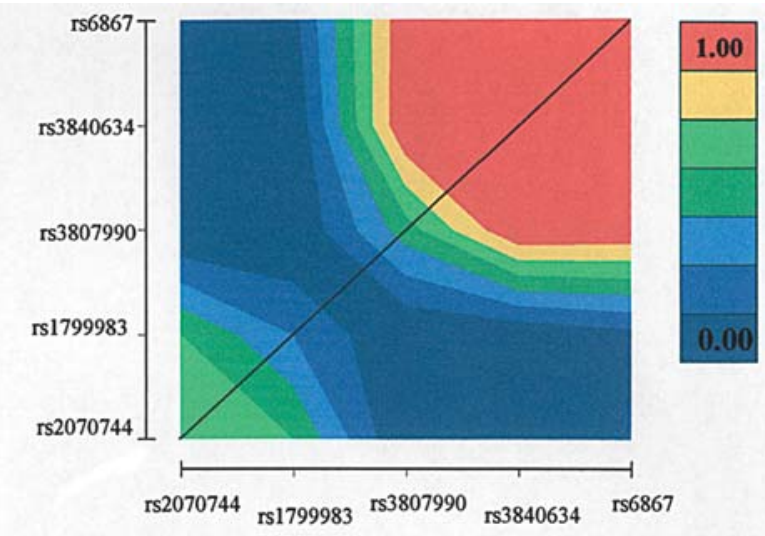

B)

\begin{tabular}{|c|c|c|c|c|}
\hline & rs1799983 & rs3807990 & rs3840634 & rs6867 \\
\hline rs2070744 & $\begin{array}{c}0.55 \\
(<0.001)\end{array}$ & $\begin{array}{c}0.04 \\
(0.397)\end{array}$ & $\begin{array}{c}-0.13 \\
(0.086)\end{array}$ & $\begin{array}{c}-0.04 \\
(0.581)\end{array}$ \\
\hline rs1799983 & - & $\begin{array}{c}0.05 \\
(0.251)\end{array}$ & $\begin{array}{c}-0.12 \\
(0.181)\end{array}$ & $\begin{array}{c}-0.02 \\
(0.809)\end{array}$ \\
\hline rs3807990 & - & - & $\begin{array}{c}-1.00 \\
(<0.001)\end{array}$ & $\begin{array}{c}0.96 \\
(<0.001)\end{array}$ \\
\hline r33840634 & - & - & - & $\begin{array}{c}-1.00 \\
(<0.001)\end{array}$ \\
\hline
\end{tabular}

C)

\begin{tabular}{|c|c|c|c|c|}
\hline & $\mathbf{r} 31799983$ & $\mathbf{r 3 3 8 0 7 9 9 0}$ & $\mathbf{r 3 3 8 4 0 6 3 4}$ & $\mathbf{r s 6 8 6 7}$ \\
\hline $\mathbf{r s 2 0 7 0 7 4 4}$ & $\begin{array}{c}0.59 \\
(<0.001)\end{array}$ & $\begin{array}{c}-0.06 \\
(0.479)\end{array}$ & $\begin{array}{c}0.16 \\
(0.062)\end{array}$ & $\begin{array}{c}-0.06 \\
(0.511)\end{array}$ \\
\hline $\mathbf{r s 1 7 9 9 9 8 3}$ & - & $\begin{array}{c}-0.15 \\
(0.118)\end{array}$ & $\begin{array}{c}0.04 \\
(0.553)\end{array}$ & $\begin{array}{c}-0.16 \\
(0.149)\end{array}$ \\
\hline $\mathbf{r} 3807990$ & - & - & $\begin{array}{c}-1.00 \\
(<0.001)\end{array}$ & $\begin{array}{c}1.00 \\
(<0.001)\end{array}$ \\
\hline $\mathbf{r 3 3 8 4 0 6 3 4}$ & - & - & - & $\begin{array}{c}-1.00 \\
(<0.001)\end{array}$ \\
\hline
\end{tabular}

Figure 1. Linkage disequilibrium between the SNPs under study in the entire population (A). D' calculated specifically for CRC cases with an associated p-value in brackets (B). D' calculated for controls, with the corresponding p-value in brackets $(C)$.

Statistical analysis. The estimation of power to detect risk or protection to CRC was calculated for each SNP using Episheet sofware according to Rothman and Roice (29). For statistical analysis of genotype distribution, test for deviation of HardyWeinberg equilibrium or two-point association studies, we employed tests adapted from Sasieni (30). These calculations were performed using the online resource at the Institute for Human Genetics, Munich, Germany (http://ihg.gsf.de). To compare allele frequencies between groups, Chi-square tests with Yates correction or Fisher exact test were also performed according to Sasieni algorithms-based software, and confirmed using Statcalc (EpiInfo 5.1, Center for Disease Control, Atlanta, GA). Haplotype analysis was performed using the Thesias software (http://www.genecanvas.org) (31). This method allows the estimation of haplotype frequencies and haplotype effects by comparing with a reference (the intercept), taken here as the most conserved one. Haplotype effects are expressed as increases/decreases in the phenotype mean with respect to that of the intercept. To perform endocohort analysis, multiple testing correction using Bonferroni adjustment were performed (p-threshold: 0.0014). Graphical representations of LD were performed using GOLD 1.0, according to Abecasis et al (32).

\section{Results}

Single polymorphism analyses. Phenotypic characteristics of the study population are shown in Table II. As a first approach, we assessed the independent effect of age and sex on the risk of developing CRC. We found an increased risk in males [OR=1.31, $\mathrm{p}=0.055,95 \%$ CI $(0.99-11.78)]$, as previously reported (33). Increasing age was associated with greater risk of CRC. Thus, individuals aged between 61 and 70 years had an OR of $5.67(\mathrm{p}<0.001)$ when compared to those under 40 years. The corresponding estimate for $\geq 70$ years was $\mathrm{OR}=11.07(\mathrm{p}<0.001)$. Gender, percentage of smokers, and body mass index $\left(\mathrm{Kg} / \mathrm{m}^{2}\right)$, was similar in both groups. Cases and controls were all caucasian from central and southern Spain.

Genotypes at all loci for cases and controls were in Hardy-Weinberg equilibrium (Table III). Pairwise linkage disequilibrium $\left( \pm D^{\prime}\right)$ between eNOS and CAV1 polymorphisms were also calculated for both cases and controls, either together or independently (Fig. 1). For CAV1, we detected a complete disequilibrium between rs3807990 and rs3840634, and also between rs6867 and rs3840634 $\left(\mathrm{D}^{\prime}=-1\right.$, $\mathrm{p}<0.001$ ). Almost complete LD was also observed for CAV1 markers rs 3807990 and $r s 6867\left(D^{\prime}=0.98, p<0.001\right)$. On the other hand, both eNOS polymorphisms (rs2070744 and rs1799983) showed a partial $L D\left(D^{\prime}=0.61, p<0.001\right)$. Both genes map to $7 \mathrm{q}$ and, according to different databases available, the physical distance between eNOS and CAV1 is $34 \mathrm{Mb}$. Thus, partial linkage disequilibrium was observed between those SNPs of eNOS and CAV1 in accordance with physical distance between the loci (Fig. 1A). When determined separatedly, D' values did not differ between cases and controls (Fig. 1B and C, respectively).

For eNOS variants, allele frequencies from rs2070744 (also named T786C) and rs1799983 (Glu298Asp) were in accordance with those previously reported for different European populations (0.47 and 0.38, respectively) (26-28). Regarding CAV1, this is the first study to our knowledge showing allele frequencies of the three SNPs under study [0.25 for rs3807990 (T), 0.19 for rs 3840634 (d) and 0.22 for rs6867 (A)]. When allele frequencies were compared between cases and controls, no statistical difference was found (data not shown). Thus, it seems that at least in our study population, eNOS and CAV1 markers do not correlate with an increased risk of developing CRC.

On average, CRC was diagnosed at 64 years, ranging from 24 to 89 years. Thus, we performed quantitative regression analysis taking into account each SNP together with the age at CRC diagnosis. No association was found (data not shown). However, we are aware of the limited sample size which is especially relevant when quantitative trait loci are assayed. On the other hand, we performed endocohort studies 
Table II. Clinical characteristics of study subjects.

\begin{tabular}{lcc}
\hline & $\begin{array}{c}\text { Controls } \\
(\mathrm{n}=550)\end{array}$ & $\begin{array}{c}\text { Cases } \\
(\mathrm{n}=360)\end{array}$ \\
\hline Age (years, mean $\pm \mathrm{SD})$ & $55 \pm 12$ & $67 \pm 11$ \\
Gender (male) & $46 \%$ & $54 \%$ \\
Smoker (ever) & $47 \%$ & $51 \%$ \\
Body mass index $\left(\mathrm{Kg} / \mathrm{m}^{2}\right)($ mean $\pm \mathrm{SD})$ & $27 \pm 4.1$ & $27 \pm 4.7$ \\
\hline Family history $(\mathrm{n}=320)$ & & \\
CRC antecedents & - & $18.7 \%$ \\
CRC aggregation & - & $4.3 \%$ \\
Nuclear CRC & - & $17.1 \%$ \\
Cancer antecedents & - & $54.3 \%$ \\
Cancer aggregation & - & $17.5 \%$ \\
Nuclear cancer & - & $50 \%$ \\
\hline
\end{tabular}

to determine if eNOS and CAV1 were modifier factors of CRC. In this way, we analyzed whether these CAV1 or eNOS alleles modified CRC heritability. Among the CRC population, almost $19 \%$ showed familiar antecedents of CRC (Table II). In most cases (17\%), these were a nuclear form of the disease ( $\geq 1$ case in 1 st-degree) whilst only $4 \%$ displayed an aggregation form of CRC ( $\geq 3$ cases in 1 st or 2 nd-degree relatives). As can be seen in Table II, CRC has an important familiar component. In our series, a high percentage of the patients showed CRC antecedents. This percentage reached $54 \%$ when each malignant cancer was computed.

Some variants displayed a positive association with the familiar manifestations of CRC (Table IV). This was especially evident for CAV1 rs3807990 (C>T), although rs6867 was also associated to familiar forms of CRC. In contrast, neither of the SNPs of eNOS were associated to a family history of CRC. However, a trend was observed in eNOS rs2070744 [OR=1.49, 95\% CI (0.97-2.3)]. The strong association between the CAV1 rs3807990 allele C, overrepresented in all nuclear $[\mathrm{OR}=1.77,95 \% \mathrm{CI}(1.1-2.8)$, $\mathrm{p}=0.02]$, aggregation $[\mathrm{OR}=2.22,95 \% \mathrm{CI}(0.9-5.3), \mathrm{p}=0.06]$, and familiar forms of $\mathrm{CRC}[\mathrm{OR}=1.92,95 \% \mathrm{CI}(1.2-3.05)$, $\mathrm{p}=0.004]$. However, in endocohort studies the appropriate control group is formed by those CRC cases that lack the parameter under study. This division significantly reduces the sample size. Consequently, these results should be considered with caution. Following this analysis, in order to get further insight into the influence of eNOS and CAV1 on CRC heritability we repeated these tests once the gene haplotypes were defined.

Haplotype analysis. Using Thesias software (31) and the data from those samples with no genotyping failure $(n=830)$, we defined the CAV1 and eNOS haplotypes. For haplotype frequency determination, cases and controls were treated together. According to the resulting LD matrix, five haplotypes for CAV1 were represented in our series, and the four possible haplotypes for eNOS were present. Haplotypes with a prevalence $<5 \%$ were not included in the study according to
Table III. Genotype distribution between cases and controls.

\begin{tabular}{|c|c|c|c|c|c|c|}
\hline Gene & $\begin{array}{l}\text { SNP } \\
\text { reference }\end{array}$ & Genotype & Cases & HWE & Controls & HWE \\
\hline \multirow[t]{6}{*}{ eNOS } & rs2070744 & $\mathrm{CC}$ & 77 & 0.897 & 122 & 0.977 \\
\hline & (T786C) & $\mathrm{TC}$ & 184 & & 273 & \\
\hline & & TT & 107 & & 152 & \\
\hline & rs1799983 & GG & 135 & 0.287 & 216 & 0.1 \\
\hline & (Glu298Asp) & TG & 160 & & 235 & \\
\hline & & $\mathrm{TT}$ & 60 & & 87 & \\
\hline \multirow[t]{9}{*}{ CAV1 } & rs3807990 & $\mathrm{CC}$ & 206 & 0.848 & 301 & 0.139 \\
\hline & $(\mathrm{C}>\mathrm{T})$ & $\mathrm{CT}$ & 132 & & 219 & \\
\hline & & $\mathrm{TT}$ & 20 & & 28 & \\
\hline & rs3840634 & ii & 240 & 0.946 & 360 & 0.901 \\
\hline & (ins/del) & id & 113 & & 171 & \\
\hline & & $\mathrm{dd}$ & 13 & & 21 & \\
\hline & rs6867 & GG & 223 & 0.556 & 318 & 0.498 \\
\hline & $(\mathrm{G}>\mathrm{A})$ & GA & 101 & & 183 & \\
\hline & & AA & 14 & & 22 & \\
\hline
\end{tabular}

Tregouet et al (32). When haplotype frequencies were compared between cases and controls, no statistical difference was observed (data not shown). Again, using haplotype analysis we obtained evidence that eNOS and CAV1 alleles are not associated with an increased risk of developing CRC.

The lack of association to CRC predisposition did not exclude the possibility of correlation with a different heritability of CRC. To test this hypothesis, haplotype frequencies were analyzed together with the age of CRC onset and the different factors regarding colon cancer familiar antecedents, or any other cancer antecedents. Quantitative analysis of both eNOS and CAV1 haplotypes did not correlate with a earlier onset of the disease. On the other hand, CAV1 haplotype TiA showed an increased prevalence among the familiar forms of CRC (Table V). However, this observation did not reach statistical significance using SEM algorithm $(p \geq 0.3)$. Conversely, when two-side cross tabulation analysis was performed comparing those patients with haplotype TiA versus the rest of the cases, the TiA haplotype was significantly associated with nuclear CRC $(\mathrm{OR}=1.83, \mathrm{p}=0.036)$ and $\mathrm{CRC}$ antecedents $(\mathrm{OR}=1.84$, $\mathrm{p}=0.02)$.

We also postulated that low penetrance alleles of eNOS and CAV1 might be genetically interacting among CRC patients. Therefore, we grouped both eNOS and CAV1 and analyzed their prevalence between cases and controls. Alternatively, we performed the same endocohort studies taking into account both genes in order to detect putative synergic effects. Surprisingly, the combination of two haplotypes: CG for eNOS, together with TiA (for CAV1) was significantly over-represented in nuclear CRC (4\% vs. $12 \%$, $\mathrm{OR}=4.4, \mathrm{p}=0.008), \mathrm{CRC}$ antecedents $(4 \%$ vs. $12 \%, \mathrm{OR}=4.2$, 
Table IV. Endocohort analysis of the CRC series.

\begin{tabular}{|c|c|c|c|c|c|c|c|c|c|}
\hline \multirow[b]{3}{*}{ Family history } & \multicolumn{8}{|c|}{ CAV1 } & \multirow[b]{3}{*}{ p-value } \\
\hline & \multicolumn{2}{|c|}{ rs3807990 $(\mathrm{C}>\mathrm{T})$} & \multirow[b]{2}{*}{ p-value } & \multicolumn{2}{|c|}{ rs3840634 (i/d) } & \multirow[b]{2}{*}{ p-value } & \multicolumn{2}{|c|}{$\operatorname{rs} 6867(\mathrm{G}>\mathrm{A})$} & \\
\hline & Controls & Cases & & Controls & Cases & & Controls & Cases & \\
\hline Nuclear CRC & 0.77 & 0.66 & 0.02 & 0.80 & 0.80 & 0.95 & 0.81 & 0.72 & 0.05 \\
\hline CRC aggregation & 0.76 & 0.59 & 0.06 & 0.80 & 0.85 & 0.53 & 0.80 & 0.83 & 0.79 \\
\hline CRC antecedents & 0.78 & 0.65 & 0.004 & 0.80 & 0.80 & 0.99 & 0.82 & 0.71 & 0.02 \\
\hline Nuclear cancer & 0.77 & 0.75 & 0.59 & 0.80 & 0.79 & 0.74 & 0.80 & 0.80 & 0.96 \\
\hline Cancer aggregation & 0.77 & 0.74 & 0.45 & 0.80 & 0.80 & 0.97 & 0.80 & 0.80 & 0.94 \\
\hline \multirow[t]{3}{*}{ Cancer antecedents } & 0.76 & 0.75 & 0.87 & 0.80 & 0.80 & 0.91 & 0.80 & 0.80 & 0.96 \\
\hline & \multicolumn{8}{|c|}{ eNOS } & \\
\hline & \multicolumn{3}{|c|}{ rs2070744 (T786C) } & \multirow{2}{*}{\multicolumn{2}{|c|}{$\mathrm{p}$-value }} & \multicolumn{2}{|c|}{ rs1799983 (Glu298Asp) } & & \multirow[b]{2}{*}{ p-value } \\
\hline Family history & \multicolumn{2}{|c|}{ Controls } & Cases & & & Controls & \multicolumn{2}{|l|}{$\overline{\text { Cases }}$} & \\
\hline Nuclear CRC & \multicolumn{2}{|c|}{0.46} & 0.48 & \multicolumn{2}{|c|}{0.77} & 0.61 & \multicolumn{2}{|l|}{0.62} & 0.72 \\
\hline CRC aggregation & \multicolumn{2}{|c|}{0.47} & 0.42 & \multicolumn{2}{|c|}{0.62} & 0.60 & \multicolumn{2}{|l|}{0.71} & 0.31 \\
\hline CRC antecedents & \multicolumn{2}{|c|}{0.47} & 0.47 & \multicolumn{2}{|c|}{0.90} & 0.60 & \multicolumn{2}{|l|}{0.63} & 0.54 \\
\hline Nuclear cancer & \multicolumn{2}{|c|}{0.46} & 0.47 & \multicolumn{2}{|c|}{0.89} & 0.61 & \multicolumn{2}{|l|}{0.61} & 0.92 \\
\hline Cancer aggregation & \multicolumn{2}{|c|}{0.48} & 0.38 & \multicolumn{2}{|c|}{0.06} & 0.60 & \multicolumn{2}{|l|}{0.65} & 0.21 \\
\hline Cancer antecedents & \multicolumn{2}{|c|}{0.47} & 0.46 & \multicolumn{2}{|c|}{0.69} & 0.60 & \multicolumn{2}{|l|}{0.62} & 0.60 \\
\hline
\end{tabular}

$\mathrm{p}=0.0061)$ and CRC aggregation (4\% vs. 14\%, not significant). Thus, we cannot exclude that both eNOS and CAV1 haplotypes might be genetically interacting among the familiar forms of CRC.

\section{Discussion}

Colorectal cancer is one of the most common neoplasms and a leading cause of death worldwide. Therefore, great investment has been made in order to gain new insight into its aetiology and how environmental and genetic factors influence the risk, onset and course of this malignancy $(33,34)$. In the present study, we have used a genomic approach to study the involvement of caveolin-1 and eNOS in CRC. The emerging evidence pointing to the role of CAV1 in cancer, together with its regulatory properties over eNOS, led us to speculate on a digenic model for CRC progression. Following this hypothesis, we studied the allele frequency distribution of five SNPs within eNOS and CAV1 in CRC cases and the general population. The eNOS polymorphism rs1799983 encodes for a missense variant in eNOS exon 7 (Glu>Asp). This is a common SNP associated with a variety of diseases such as hypertension, pre-eclampsia, placental abruption or myocardial infarction (35-37). On the other hand, eNOS rs2070744 is a C>T conversion within intron 4 and it also has been studied in ovarian cancer and renal diseases $(22,38)$. The wide range of phenotypes displayed by these variations proves the involvement of nitric oxide in multiple pathways, including carcinogenesis and tumor progression (39). However, our study firmly supports that there is no association between these eNOS polymorphisms and the susceptibility of CRC in the Spanish population.
Whenever negative associations are reported, the power of the study is questioned. However, we must state that according to the patient/control ratio, sample size and the allele prevalence for each marker, we should be able to detect positive OR $\geq 1.5$ with a power of $80 \%$ and $\geq 1.6$ in a more conservative fashion (90\%) (Table VI). Therefore, the effect of these eNOS and CAV1 alleles on CRC risk, if present, would be very low. We found evidence of association between eNOS rs2070744 and cancer aggregation (O.R.=1.49, p=0.06). When eNOS haplotype distribution was studied in this sub-group, the - $\mathrm{T}$ background $(\mathrm{CT}+\mathrm{GT})$ was also significantly increased in the families with cancer aggregation $(\mathrm{OR}=2.9, \mathrm{p}=0.022)$. However, this association did not support a more conservative analysis and multiple testing corrections (data not shown).

We studied the prevalence of three SNPs within CAV1 in our study population. The rationale for this study was that some authors found caveolin-1 overexpressed in experimental colon adenocarcinoma and its expression in human colon cancer cell lines directly correlates with their growth rate (11). Some studies with tissues from human prostate, breast and colon adenocarcinoma also showed overexpression of CAV1 $(15,16)$. In contrast, previous reports using xenographs in nude mice showed that tumor formation in vivo resulted in the selection of cells with lower basal levels of caveolin-1 (10). Moreover, 7q31.1 is a frequently deleted region in different carcinomas, and tumor suppressor activity in vitro was reported $(40,41)$. Thus, CAV1 has been considered a tumor suppressor gene (13). With this antecedents, it seemed necessary to circumvent the experimental designs and perform a genomic approach to elucidate the role of CAV1 in CRC. Following this approach, we were not 
Table V. Haplotype frequencies within CRC cases.

\begin{tabular}{|c|c|c|c|c|c|c|c|c|c|}
\hline \multirow[b]{2}{*}{ Haplotype } & \multicolumn{3}{|c|}{ Nuclear CRC } & \multicolumn{3}{|c|}{ CRC aggregation } & \multicolumn{3}{|c|}{$\mathrm{CRC}$ antecedents } \\
\hline & Controls & Cases & OR (p-value) & Controls & Cases & OR (p-value) & Controls & Cases & OR (p-value) \\
\hline \multicolumn{10}{|l|}{ eNOS } \\
\hline $\mathrm{CT}$ & 0.31 & 0.33 & $1.2(0.54)$ & 0.32 & 0.22 & $0.77(0.67)$ & 0.32 & 0.32 & $1.1(0.76)$ \\
\hline CG & 0.14 & 0.19 & $1.4(0.28)$ & 0.15 & 0.27 & $2.1(0.30)$ & 0.15 & 0.19 & $1.4(0.36)$ \\
\hline $\mathrm{TT}$ & 0.09 & 0.09 & $1.2(0.71)$ & 0.09 & 0.13 & $1.6(0.59)$ & 0.09 & 0.09 & $1.1(0.92)$ \\
\hline TG & 0.44 & 0.38 & $1.0^{\mathrm{a}}$ & 0.43 & 0.37 & $1.0^{\mathrm{a}}$ & 0.43 & 0.40 & $1.0^{\mathrm{a}}$ \\
\hline \multicolumn{10}{|l|}{ CAV1 } \\
\hline $\mathrm{CiG}$ & 0.57 & 0.45 & $0.7(0.25)$ & 0.55 & 0.45 & $0.79(0.79)$ & 0.57 & 0.44 & $0.68(0.24)$ \\
\hline $\mathrm{CdG}$ & 0.19 & 0.21 & $1.0^{\mathrm{a}}$ & 0.19 & 0.20 & $1.0^{\mathrm{a}}$ & 0.19 & 0.21 & $1.0^{\mathrm{a}}$ \\
\hline $\mathrm{TiG}$ & 0.05 & 0.04 & $0.7(0.59)$ & 0.04 & 0.15 & $4.2(0.16)$ & 0.04 & 0.04 & $0.92(0.89)$ \\
\hline \multirow[t]{2}{*}{ TiA } & 0.18 & 0.29 & $1.4(0.37)$ & 0.20 & 0.20 & $0.95(0.94)$ & 0.18 & 0.29 & $1.4(0.3)$ \\
\hline & \multicolumn{3}{|c|}{ Nuclear CRC } & \multicolumn{3}{|c|}{ CRC aggregation } & \multicolumn{3}{|c|}{$\mathrm{CRC}$ antecedents } \\
\hline Haplotype & Controls & Cases & OR (p-value) & Controls & Cases & OR (p-value) & Controls & Cases & OR (p-value) \\
\hline \multicolumn{10}{|l|}{ eNOS } \\
\hline $\mathrm{CT}$ & 0.33 & 0.30 & $0.92(0.71)$ & 0.34 & 0.30 & $0.82(0.36)$ & 0.34 & 0.23 & $0.63(0.15)$ \\
\hline $\mathrm{CG}$ & 0.15 & 0.16 & $1.2(0.58)$ & 0.15 & 0.16 & $1.0(0.92)$ & 0.15 & 0.16 & $0.97(0.94)$ \\
\hline $\mathrm{TT}$ & 0.08 & 0.09 & $1.2(0.59)$ & 0.09 & 0.09 & $0.95(0.9)$ & 0.08 & 0.15 & $1.8(0.15)$ \\
\hline TG & 0.43 & 0.43 & $1.0^{\mathrm{a}}$ & 0.42 & 0.44 & $1.0^{\mathrm{a}}$ & 0.42 & 0.45 & $1.0^{\mathrm{a}}$ \\
\hline \multicolumn{10}{|l|}{ CAV1 } \\
\hline $\mathrm{CiG}$ & 0.56 & 0.54 & $0.86(0.50)$ & 0.56 & 0.53 & $0.88(0.65)$ & 0.56 & 0.54 & $0.88(0.60)$ \\
\hline $\mathrm{CdG}$ & 0.19 & 0.21 & $0.65(0.38)$ & 0.19 & 0.21 & $0.86(0.82)$ & 0.19 & 0.20 & $0.69(0.45)$ \\
\hline $\mathrm{TiG}$ & 0.05 & 0.04 & $0.91(0.71)$ & 0.04 & 0.04 & $0.98(0.97)$ & 0.05 & 0.04 & $0.97(0.92)$ \\
\hline TiA & 0.20 & 0.20 & $1.0^{\mathrm{a}}$ & 0.20 & 0.21 & $1.0^{\mathrm{a}}$ & 0.19 & 0.20 & $1.0^{\mathrm{a}}$ \\
\hline
\end{tabular}

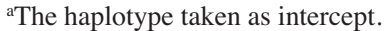

Table VI. Minimum odds ratio detectable according to allele frequencies, sample size and the case/control ratio.

\begin{tabular}{llccc}
\hline Gene & SNP reference & Frequency & Power 80\% & Power 90\% \\
\hline eNOS & rs2070744(C) & 0.472 & O.R. $>1.5$ & O.R. $>1.6$ \\
& rs1799983(T) & 0.385 & O.R. $>1.5$ & O.R. $>1.6$ \\
& & & & \\
CAV1 & rs3807990(T) & 0.251 & O.R. $>1.6$ & O.R. $>1.7$ \\
& rs3840634 (d) & 0.192 & O.R. $>1.6$ & O.R. $>1.7$ \\
& rs6867 (A) & 0.217 & O.R. $>1.6$ & O.R. $>1.7$ \\
\hline
\end{tabular}

able to find any direct association between rs3807990, rs3840634 or rs6867, and an altered likelihood of developing CRC. Therefore, it seems that these SNPs are not tumor markers in our population.

On the other hand, we detected a correlation between rs3807990 and CRC aggregation, nuclear forms and familiar antecedents of CRC (Table IV). In these groups, we found an over-representation of the allele $\mathrm{T}$ in all familial forms. In addition, rs6867 (G>A) was also associated with the familiar manifestations of CRC. Taken together, the results suggest that CAV1 alleles might modify $\mathrm{CRC}$ heritability. As expected, when haplotype distribution was studied, the prevalence of the TiA haplotype was increased among the risk groups. Moreover, the analysis performed taking eNOS and CAV1 together suggested an additive effect over both alleles. Further analysis should be done in order to confirm this hypothesis and to elucidate the true role that eNOS and CAV1 alleles on CRC aetiology.

\section{Acknowledgements}

This study was supported by Ministerio de Ciencia y Tecnologia (the Spanish Ministry of Science and Technology) PROFIT 010000-2004-69. J.L.R., E.M. and R.R.L. hold a Torres Quevedo fellowship from the Ministerio de Educación y Ciencia (the Spanish Ministry of Education and Science). We thank Ana Salinas and Ma Carmen Rivero for technical assistance and Antonio Gonzalez for critical review. 


\section{References}

1. Engelman JA, Zhang X, Galbiati F, et al: Molecular genetics of the caveolin gene family: implications for human cancers, diabetes, Alzheimer disease, and muscular dystrophy. Am J Hum Genet 63: 1578-1587, 1998 .

2. Li S, Okamoto T, Chun M, et al: Evidence for a regulated interaction between heterotrimeric $\mathrm{G}$ proteins and caveolin. $\mathrm{J}$ Biol Chem 270: 15693-15701, 1995.

3. Barouch LA, Harrison RW, Skaf MW, et al: Nitric oxide regulates the heart by spatial confinement of nitric oxide synthase isoforms. Nature 416: 337-339, 2002.

4. Shajahan AN, Tiruppathi C, Smrcka AV, Malik AB and Minshall RD: G-betagamma activation of Src induces caveolaemediated endocytosis in endothelial cells. J Biol Chem 279: 48055-48062, 2004.

5. Kurzchalia TV and Parton RG: Membrane microdomains and caveolae. Curr Opin Cell Biol 11: 424-431, 1999.

6. Lavie Y, Fiucci G and Liscovitch M: Up-regulation of caveolae and caveolar constituents in multidrug-resistant cancer cells. J Biol Chem 273: 32380-32383, 1998.

7. Drab M, Verkade P, Elger M, et al: Loss of caveolae, vascular dysfunction, and pulmonary defects in caveolin-1 gene-disrupted mice. Science 293: 2449-2452, 2001

8. Betz RC, Schoser BG, Kasper D, et al: Mutations in CAV3 cause mechanical hyperirritability of skeletal muscle in rippling muscle disease. Nat Genet 28: 218-219, 2001.

9. De Paula F, Vainzof M, Bernardino AL, McNally E, Kunkel LM and Zatz M: Mutations in the caveolin-3 gene: When are they pathogenic? Am J Med Genet 99: 303-307, 2001.

10. Bender FC, Reymond MA, Bron C and Quest AF: Caveolin-1 levels are down-regulated in human colon tumors, and ectopic expression of caveolin-1 in colon carcinoma cell lines reduces cell tumorigenicity. Cancer Res 60: 5870-5878, 2000.

11. Patlolla JM, Swamy MV, Raju J and Rao CV: Overexpression of caveolin-1 in experimental colon adenocarcinomas and human colon cancer cell lines. Oncol Rep 11: 957-963, 2004.

12. Chene L, Giroud C, Desgrandchamps F, et al: Extensive analysis of the 7q31 region in human prostate tumors supports TES as the best candidate tumor suppressor gene. Int J Cancer 111: 798-804, 2004

13. Engelman JA, Zhang XL, Galbiati F and Lisanti MP: Chromosomal localization, genomic organization, and developmental expression of the murine caveolin gene family (Cav-1, -2, and -3): Cav-1 and Cav-2 genes map to a known tumor suppressor locus (6-A2/7q31). FEBS Lett 429: 330-336, 1998.

14. Lin SY, Yeh KT, Chen WT, Chen HC, Chen ST and Chang JG: Promoter CpG methylation of caveolin-1 in sporadic colorectal cancer. Anticancer Res 24: 1645-1650, 2004.

15. Yang G, Truong LD, Timme TL, et al: Elevated expression of caveolin is associated with prostate and breast cancer. Clin Cancer Res 4: 1873-1880, 1998.

16. Fine SW, Lisanti MP, Galbiati F and Li M: Elevated expression of caveolin-1 in adenocarcinoma of the colon. Am J Clin Pathol 115: 719-724, 2001.

17. Schubert W, Frank PG, Woodman SE, et al: Microvascular hyperpermeability in caveolin-1 (-/-) knock-out mice. Treatment with a specific nitric-oxide synthase inhibitor, L-name, restores normal microvascular permeability in Cav-1 null mice. J Biol Chem 277: 40091-40108, 2002.

18. Bucci M, Gratton JP, Rudic RD, et al: In vivo delivery of the caveolin-1 scaffolding domain inhibits nitric oxide synthesis and reduces inflammation. Nat Med 6: 1362-1367, 2000.

19. Rao CV: Nitric oxide signaling in colon cancer chemoprevention. Mutat Res 555: 107-119, 2004.

20. Mortensen K, Christensen IJ, Nielsen HJ, Hansen U and Larsson LI: High expression of endothelial cell nitric oxide synthase in peritumoral microvessels predicts increased diseasefree survival in colorectal cancer. Cancer Lett 216: 109-114, 2004.
21. Riener EK, Hefler LA, Grimm C, et al: Polymorphisms of the endothelial nitric oxide synthase gene in women with vulvar cancer. Gynecol Oncol 93: 686-690, 2004.

22. Hefler LA, Ludwig E, Lampe D, et al: Polymorphisms of the endothelial nitric oxide synthase gene in ovarian cancer. Gynecol Oncol 86: 134-137, 2002.

23. Ghilardi G, Biondi ML, DeMonti M, et al: Independent risk factor for moderate to severe internal carotid artery stenosis: T786C mutation of the endothelial nitric oxide synthase gene. Clin Chem 48: 989-993, 2002.

24. Ghilardi G, Biondi ML, Cecchini F, DeMonti M, Guagnellini E and Scorza R: Vascular invasion in human breast cancer is correlated to $\mathrm{T} \rightarrow 786 \mathrm{C}$ polymorphism of NOS3 gene. Nitric Oxide 9: 118-122, 2003.

25. Devuyst O: Variable renal disease progression in autosomal dominant polycystic kidney disease: a role for nitric oxide? $\mathbf{J}$ Nephrol 16: 449-452, 2003.

26. Persu A, Stoenoiu MS, Messiaen T, et al: Modifier effect of ENOS in autosomal dominant polycystic kidney disease. Hum Mol Genet 11: 229-241, 2002.

27. Colombo MG, Paradossi U, Andreassi MG, et al: Endothelial nitric oxide synthase gene polymorphisms and risk of coronary artery disease. Clin Chem 49: 389-395, 2003.

28. Fernandez ML, Ruiz R, Gonzalez MA, et al: Association of NOS3 gene with metabolic syndrome in hypertensive patients. Thromb Haemost 92: 413-418, 2004.

29. Rothman KJ and Boice JD: Epidemiologic Analysis With a Programable Calculator. NIH Publication, pp79-1649, 1979.

30. Sasieni PD: From genotypes to genes: doubling the sample size. Biometrics 53: 1253-1261, 1997.

31. Tregouet DA, Escolano S, Tiret L, Mallet A and Golmard JL: A new algorithm for haplotype-based association analysis: the Stochastic-EM algorithm. Ann Hum Genet 68: 165-177, 2004

32. Abecasis GR and Cookson WO: GOLD-graphical overview of linkage disequilibrium. Bioinformatics 16: 182-183, 2000.

33. Potter JD: Related colorectal cancer: molecules and populations. J Natl Cancer Inst 91: 916-932, 1999.

34. Dong SM, Traverso G, Johnson C, et al: Detecting colorectal cancer in stool with the use of multiple genetic targets. J Natl Cancer Inst 93: 858-865, 2001.

35. Shimasaki Y, Yasue H, Yoshimura M, et al: Association of the missense Glu298Asp variant of the endothelial nitric oxide synthase gene with myocardial infarction. J Am Coll Cardiol 31: 1506-1510, 1998

36. Miyamoto Y, Saito Y, Kajiyama N, et al: Endothelial nitric oxide synthase gene is positively associated with essential hypertension. Hypertension 32: 3-8, 1998.

37. Yoshimura T, Yoshimura M, Tabata A, et al: Association of the missense Glu298Asp variant of the endothelial nitric oxide synthase gene with severe preeclampsia. J Soc Gynecol Investig 7: $238-241,2000$

38. Wang Y, Kikuchi S, Suzuki H, Nagase S and Koyama A: Endothelial nitric oxide synthase gene polymorphism in intron 4 affects the progression of renal failure in non-diabetic renal diseases. Nephrol Dial Transplant 14: 2898-28902, 1999.

39. Lala PK and Chakraborty C: Role of nitric oxide in carcinogenesis and tumour progression. Lancet Oncol 2: 149-156, 2001.

40. Koleske AJ, Baltimore D and Lisanti MP: Reduction of caveolin and caveolae in oncogenically transformed cells. Proc Natl Acad Sci USA 92: 1381-1385, 1995.

41. Engelman JA, Wykoff CC, Yasuhara S, Song KS, Okamoto T and Lisanti MP: Recombinant expression of caveolin-1 in oncogenically transformed cells abrogates anchorage-independent growth. J Biol Chem 272: 16374-16381, 1997. 